\title{
Teacher Resources Online
}

SUSAN NICHOLS

University of South Australia

AMY MAYNARD

University of South Australia

CHRISTOPHER BROWN

University of South Australia

\begin{abstract}
The role of the internet is becoming ever more significant in the production and circulation of resources for literacy teaching, and in the process is changing teachers' relationships with educational resources and professional communities. In this paper, we present case studies of four online resource networks established specifically for educational practitioners: TeacherTube, TES, TWRC Tank and Teacher Toolbox. We explore how and why the managers of these sites engage teachers, the online activities of educators using the sites, and the kinds of literacy teaching resources that are available to them. Based on an analysis of literacy teaching resources and associated activity on these websites, we argue that teacher professionalism in contemporary times involves new digital literacy practices in addition to conventional modes of using textual resources in teaching.
\end{abstract}

\section{Introduction}

The role of the internet is becoming ever more significant in the production and circulation of resources for teaching and in the process is changing teachers' relationships with resources and professional communities. In this paper, we present case studies of four online resource networks established specifically for educational practitioners. We will explore how and why the managers of these sites engage teachers, the online activities of educators using the sites, and the kinds of resources available to them.

The title 'teacher resources online' can be read in four ways. First, in digital spaces one can find teacher resources, that is, materials which can be used by teachers. Second, teachers are producing resources and circulating them online so, in that sense, the resources are 'teacher resources' not just materials produced by others for the use of teachers. Third, teachers themselves are the resources. Their professional knowledge offered in online forums is understood by other educators as having value. Finally, teachers' presence online means they can be targeted by agents wishing to sell goods or ideas; in this sense, teachers are valuable resources for those wanting to sell web-space to such agents.

Developments in digital technology have had profound effects on the nature of literacy teaching resources, the means of production and distribution, and the diversity of agents in the marketplace. There is a burgeoning of government supported and mandated online curriculum and professional development (Derringer, 2010; Downer et al, 2009; Meyen \& Hang, 2005). However official systems are contesting the 
ground with commercial corporations, NGOs and entrepreneurial individuals. Direct distribution companies, which have long experience in circulating catalogues and materials to schools, have digitised their operations. Every educational publishing house and professional association for teachers has a web-site which offers downloadable files and elements of user interactivity, free or by subscription.

Our focus in this paper is on websites established outside of official education systems which support teachers' production and circulation of literacy resources. One of the most significant changes enabled by the internet is the erosion of the distinction between consumers and producers (Comor, 2011). A broad social movement in the production and sharing of digital media products is manifesting in sites like YouTube and Facebook. Teachers are joining this movement by sharing videos on TeacherTube, buying and selling resources on sites like Teacher Marketplace, and recommending and commenting on resources in edublogs. This activity to date has received very little scholarly attention.

This study has taken place in a climate of debate about the regulation of literacy teaching in which resources have played a key part. Official policy on the resourcing of literacy teaching has become associated with moves to standardise curriculum and assessment. Standardising resources aims to ensure that the curriculum will be delivered consistently in every site of practice. In the United States, the No Child Left Behind Act (NCLB) mandated specific published programs, characterised by an emphasis on phonics - teaching children to decode based on lettersound relationships (Fang, Fu, \& Lamme, 2004, Handsfield, Crumple,r \& Dean, 2010). In a case study of one such program, Read Well, Owen (2010) describes how it was presented as a total package excluding all other materials, incorporating teacher scripts into lesson plans and student texts. In the United Kingdom, the National Literacy Strategy while less prescriptive regarding content than NCLB, has been similarly directive regarding literacy teaching practices. Here too, the production and circulation of resources has been an integral part of the effort to achieve consistency. Again, the emphasis was on the totality of the package excluding the need to look elsewhere: "The training materials... were originally conceived of as a total approach to literacy teaching, not as an add-on to current practice" (Bryan, 2004, p.142).

The question of why teachers may wish to search for resources outside of officially supported domains has been addressed in one study of teachers' "selfgenerated online communities" (Hur \& Brush, 2009, p. 279). Based on a content analysis of more than 2,000 posts and 23 interviews, the study found that "teachers searched for very specific ideas that were appropriate for their unique teaching situations" (p. 295) and sought "ideas that were proven to work in actual classrooms" (p. 296). Consistent with this, Reidy and Carlson's (2010) small interview study found that teachers consulted with colleagues and searched independently to find materials they could tailor for specific pedagogic and curricular purposes.

Our study, part of a larger project on the resourcing of literacy teachers, takes a case study approach to the investigation of digital resource provision. For the very reason of the vastness and dynamism of the growing digital resource network, it can be valuable to isolate particular instances of the phenomenon. These cases enable us to identify significant issues associated with the characteristics of literacy resources provided online, and the nature of educators' participation in digital resource communities. 


\section{Case Selection and Methodology}

We have selected four websites for analysis, on the basis of six criteria: (1) They have been established specifically for teachers; (2) Resources are offered on site; (3) Literacy is one of the areas addressed in resource provision; (4) They include a significant interactive component, such as the opportunity to upload resources, comment and discuss; (5) There is evidence of significant ongoing usage; (6) The sites are produced from outside government-run education systems. In a climate of intensified regulation of curriculum delivery, this non-official production domain is receiving little scrutiny.

Each of these websites provides resources for free. This was not one of our criteria but rather emerges as a characteristic of those sites which have significant teacher participation. In other words, sites that have high levels of activity are those where teachers do not have to enter the role of consumer; their activity is not constituted as 'shopping'.

In order to identify these cases, two researchers spent two weeks in general exploration of online resource sites, with a particular focus on those which directly targeted teachers and had interactive elements. This was followed by 4 weeks of close monitoring of selected sites and analysis of the kinds of resources available and types and levels of activity in various categories. Publicly available information including user profiles, download levels, resource types, number of discussion topics and responses was gathered and analysed. Statements made by the organisations or individuals hosting the sites were examined for what they indicated about intentions, motives, strategies and assumptions.

The selected websites include two run by organisations and two run by individuals. TeacherTube is an educational offshoot of Youtube and operates as an open-access platform for sharing digital files, mainly in video form. The UK based Times Educational Supplement (TES) is provided by a commercial publisher and hosts a resource area specifically for teachers within its website. Two educational blogs which also offer resources have been selected: the US-based TWRC Tank and the Australian Teacher Toolbox.

\section{TeacherTube}

The TeacherTube website was launched on March $6^{\text {th }} 2007$, with the goal of "provid[ing] an online community for sharing instructional videos" (TeacherTube, 2010). While other file formats are supported, including audio and document files, videos comprise more than $90 \%$ of the total resources. A high rate of activity happens on this platform with thousands of videos uploaded every month.

What makes a TeacherTube video 'instructional' as distinct from a YouTube video? The site managers describe the videos in terms of two categories: "professional development with teachers teaching teachers' and 'videos designed for students to view in order to learn a concept or skill" (TeacherTube, 2010). Thus, the assumption is that the video has a teaching role; viewing it enables either a teacher or a student to acquire knowledge or competence.

The "community" aspect of TeacherTube indicates an expectation that users will be involved in and sustain the service. Avenues to enable this include uploading and downloading files, rating resources, commenting and initiating or joining a group or forum. At the time of this study there were approximately 805,000 registered users of the site and 170,000 resources available. The largest group of registered users were from the United States (more than half), with other English-speaking countries (UK, Australian and Canada) together making up approximately six percent. Numbers from 
other countries, in relation to the total, were not sufficient to make up meaningful percentages; however, they may still represent a significant trend in their national contexts. For instance, there were 3,916 members from India and 1,768 members from Mexico.

When searching for resources, users can select by 'Channel' which means category (e.g., level, elementary, high) or subject area. The term 'literacy' is not used; instead the separate categories of 'reading' and 'writing' are given. These two categories combined made up $14 \%$ of resources in the video format, fourth behind Science (20\%), Mathematics (18\%) and Technology (16\%). The situation for document files was different. Here reading and writing combined to make up $23 \%$ of resources offered. This suggests that print continues to be an important modality in the production and distribution of literacy resources.

The Writing Channel was selected for closer examination. Of the more than 170 pages of titles offered, the first 20 screens were taken as a sample, a total of 320 videos, all of which had been uploaded within the month prior to viewing. Videos from this corpus were then sorted according to the number of times they have been viewed.

More than a third of these videos had not received any views. Of those that had, most received fewer than fifty views. Within this corpus, the most popular videos judging from the number of views were:

- Nouns grammar rock (814)

- The semi-colon: it's not just a fancy comma (327)

- HotKeys (232)

- “Awesome Dog" narrative writing lesson (222)

- Comma 6 (212)

- Story Project Intro (211)

- Conferring with student writers (203)

- Persuasive writing (202)

- Poetry with Technology (195)

- Slippery slope (186)

"Nouns grammar rock" is an animated song to a chirpy hillbilly soundtrack. Each verse is an episode in the simple narrative of a young girl crossing America on a train; the lyrics proclaim that 'every place that you can go and every person you can know has a name'. The animation is obviously professionally produced but no producer or creator acknowledgment is provided. As the clip received no comments, we can only speculate on the reasons for its popularity. Factors may include its focus on a foundational grammatical concept, the hope that music and animation may be motivating for children, and the inclusion of iconic American symbols like the railroad and the Statue of Liberty. It ticks quite a few boxes.

Four of the top-ranking items in our sample have teacher presenters and focus on a specific teaching point. As an example, the "Awesome Dog" narrative writing lesson shows a teacher in front of a 'class' that consists of just two 'students'. She is holding a poster showing various dogs and asks the children to volunteer descriptions to illustrate the point that it is not enough to simply say "I have an awesome dog". She has a script behind the poster which becomes visible at one point when she is in danger of dropping it. Production on these clips is very simple with only one appearing to have any professional editing. 


\section{Interference on the Writing Channel}

Three of the top-ranking items in our sample had little or nothing to do with the teaching of writing. "Comma 6" is one of several 'comma' clips added by the user Jjwrey. This 1 second video simply shows a comma descending into a sentence reading "Goku, you are the weakest Saiyan of all" (a reference to characters in the popular 1990s animation Dragon Ball). "Persuasive writing" is actually a Pepsi advertisement featuring Michael Jackson. "Slippery Slope" at first looked like a news broadcast reporting a Supreme Court decision but became a personal rant about corporations and unions 'implanting the legislators of their choice'.

TeacherTube forums purport to support an active community of educators discussing professional topics. However, in the "English and Grammar" forum 29 of 31 topics were completely unrelated to education. They included advertising, sports results and romantic reflections. One of only two grammar-related posts, "Proper use of problem words", contained a screen's worth of random words and phrases which had to be scrolled through before finding the post proper, a link to a university website.

So it appears that more than one community is using TeacherTube. Those resources and discussions that seemed to promise 'proper' literacy instruction were the most highly subscribed suggesting that educators are searching for legitimate, authorised knowledge about literacy teaching and ways to solve literacy problems. Other user groups are networking through TeacherTube for the purposes of advertising, political propaganda, play or subversion.

\section{Times Educational Supplement (TES)}

TES is a magazine produced by TSL Education. The online offshoot of this magazine, advertises itself as "the largest network of teachers in the world" (TES, 2011, n.p.) with 1.8 million registered users. The largest group of these (just over a third) were from the United Kingdom. The United States (3\%) and Australia (2\%) were the only two other countries with significant representation, meaning that the majority of users came from diverse locations. TES has an active community as evidenced by the numbers of users online at any one time. When last checked, the statistics showed 2,171 forum posts in the previous 24 hours and 56 people currently online.

The Resources area is described as "the space for teachers to share free learning materials including lesson plans, activities, games, teaching ideas and worksheets... [to] upload, adapt, edit and download classroom resources" (TES, 2011 n. p.). When examined, there were over 146,000 resources available. The Resources area is managed by the TES Resource Team which is active in monitoring the site and in encouraging teachers to become 'content partners' (i.e., to upload resources). At the time of writing, a competition was in progress with a $£ 4,000$ prize for the school whose staff uploaded the most 'quality resources' to the teacher resource section of the website.

Resources are grouped according to stage (Early Years Foundation, Primary \& Secondary) with categories also for Whole School and Special Education Needs. Under Early Years, there are sub-categories for 'literacy and language' and 'communication'. In the Primary phase, English (23\%) and Mathematics (22\%) are the categories with the most resources available.

We examined more closely the resources available in the English area for Key Stage 1 (ages 5 - 7) and Key Stage 2 (ages 8 -12). Resources in English are further sorted into categories including phonics, narrative texts, word work, speaking and 
listening and others. Looking at the number of resources available gives some indication of the priorities of those using the site. In rank order the top five resource categories were as shown in Table 1:

Table 1

Top Five English Resource Categories by Number of Resources: TES

\begin{tabular}{|l|l|}
\hline Learning Area and Key Stage & No of Resources \\
\hline KS1 Phonics & 2529 \\
\hline KS1 Word Work & 1506 \\
\hline KS2 Word Work & 1346 \\
\hline KS2 Narrative Texts & 1124 \\
\hline KS1 Narrative Texts & 1012 \\
\hline
\end{tabular}

There is a clear emphasis on curriculum elements associated with the mandated National Literacy Strategy, particularly the inclusion of phonics in literacy teaching at Key Stage 1.

Within each category, resources are listed with the most popular at the top. Many of the most popular resources take the form of collections of materials integrated into a single plan or package. An example is VCOP Early Morning Activities which was most popular in four Key Stage 2 categories: Word Work, Narrative Texts, Nonfiction Texts and Sentence Structure and Punctuation. VCOP is an acronym for Vocabulary, Connectives, Openers and Punctuation, which represents a set of strategies for writing UK teachers are strongly encouraged to emphasize.

Those putting together resource packages sometimes draw from other resources offered on the TES site to do so. An example is the highly popular VCOP Resource Bank contributed by cariad 2 who describes it in the following terms:

I've pulled together various resources such as quick fire activities that I'd previously uploaded separately, and games and links suggested by other posters (notably bluerose) into 1 document.

The reference to blue rose, indicates the 'content partner' responsible for the aforementioned VCOP Early Morning Activities.

Clicking on a provider's name takes users to their profile. The total number of views to date for that provider's resources is included. In the case of cariad2, she will soon reach a million views, a very significant level of activity.

Popular resources tend to receive more comments, often over 100, and these give some insight into what teachers find so attractive about them. Recurring themes in comments include that the resources save teachers time, make life easier, help to fill in gaps in knowledge, have become available just in time and are appreciated for the work that has gone into their production:

Thank you so much. you (sic) have saved me valuable planning time. (joodle1602 on Phase 3 Lesson Plan)

Well done putting this altogether! Are we really "working together" and not "reinventing the wheel'??? Fabulous! What a time saver. Imagine being a 
beginning teacher and being given this resource? Thank you. (marielewis on Back to School Pack)

Vcop ideas bank is a great resource. Just started teaching re sentence structure and subordinate clauses and this is perfect! Thank you. (janeted on VCOP Resource Bank)

It is unlikely that a 'fame factor' or established expert identity has any great influence in the TES resource network. Many content providers do not give any personal information. cariad2 offers a self-consciously wry biography: "I was born. Got bigger. Got older. Drank lots of tea. Not dead yet."

Insider humour, reflecting the figure of the battered but good natured classroom veteran, was also evident in the highest rated post in a TES forum, "Funniest thing you've seen when marking work" had generated 222 replies. Teachers shared humorous mistakes, unfortunate sentences and combinations of words found in students' work, reminiscent of the lists that used to circulate by email and be pinned up on staffroom noticeboards.

Indeed there is some indication that attempts by individuals to use the site for building a professional profile is not well regarded by the community. The author of a forum post "Why it is difficult to reduce educational underachievement in Anglophone countries?" included a link to her own website (English Spelling Problems, 2007), revealing her to be Masha Bell, self-identified independent literacy researcher and author of several books. Her post sparked much commentary with the first of many mainly critical replies appearing just three minutes after the initial topic was posted. Some commentators criticised Bell for having a well known obsession, or 'hobby horse', which disqualified her from being taken seriously.

TES appears to have succeeded to a degree in creating a community of resourceful teachers. Indicators of its success are the immediacy with which users respond to new posts and resources, the constant activity of resource uploading, and the stated appreciation of users for the service provided by their peers. Literacy resources which are closely linked to the official curriculum and which consist of multiple elements combined into a package are most likely to attract attention and uptake.

\section{Think, Wonder, Reflect, Connect (TWRCTank)}

TWRC is pronounced 'twirk' (to rhyme with 'work'). This educational blog created by an American, Julie Niles Peterson (2011), contains a substantial searchable archive of resources. Unlike the first two sites, TWRC Tank specifically focuses on literacy. Literacy is defined in terms of phonemic awareness, phonics, fluency, vocabulary and comprehension, the so-called 'Big Five' skills incorporated into the No Child Left Behind Act (NCLB) which mandated the beginning reading curriculum in the USA. Vocabulary and Comprehension are given particular emphasis as key categories in the site's resources area.

The resource collection does not include the kinds of activities that can be imported directly into the classroom (e.g., worksheets); it focuses instead on promoting knowledge and reflection on literacy teaching. Resources provided on site include links to essays, pdf files of academic articles, videos, and podcasts. These resources are presented as a curated collection through Niles Peterson's personal introductions to items (e.g., "This really influenced my thoughts on reading", or "In my opinion, this is the key to the achievement gap"). The blog and its resources also 
connect readers to events such as the United States Department of Education's Reading Institute in Anaheim (2010) at which Niles Peterson presented.

Niles Peterson is very conscious of interacting with her users, and promoting feedback. She also uses Twitter and Facebook to connect with her audience. Her Twitter feed had 1,184 followers when last checked (June 5, 2012). Her blog posts often include questions, for example "If you could share one thing with parents that you think would really have an impact on their child's academic success, what would it be?" She weaves personal reflections with her professional advice. For example, the blog post "Common Causes of Comprehension Difficulties" begins by explaining that her husband, Michael, had difficulty understanding the narrative of fiction books, but could successfully read instruction manuals. She goes on to explain that in order to comprehend writing, the reader must actively ask questions in order to pursue coherence. After sharing these personal anecdotes, Niles Peterson provides links to articles, books and videos that explain why some readers struggle with comprehension.

This strategy of connecting the personal and the professional is also taken up by many commenters, as in the following response to the post about comprehension difficulties. Michelle Breum refers to a recommended book, links this to her own experience, and then comes back to the substance of Niles Peterson's post:

I read the first chapter of I Read, but I Don't Get It. I was a fake reader like the author. Comprehension doesn't happen unless a reader puts in some mental energy along with a purpose for reading. This is something I did not know before attending college. I remember spacing out and needing to reread many times. This type of frustration made me avoid reading as a child and teenager. [ ... ] I'm glad you addressed this important topic. It made me remember my struggles. Reading is so much more than phonics. I'm going to have to put in some TWRC time into this topic and find a way to share some helpful advice with parents to improve a child's reading comprehension on my blog.

As the comment indicates, Breum is a teacher and also an active blogger. The site thus operates as a space for sustaining and expanding a professional community that Niles Peterson and her commentators are contributing to and drawing from.

The nature of this community and how it is positioned in relation to other literacy promotion groups is indicated by the blog post with the most comments (87). Titled "How I Lost My Reading Specialist Position and What Makes a Good Literacy Coach?", it details how the author was fired from a school for failing to adhere strictly to the mandated literacy program, Read 180. Evidently Niles Peterson has a conflicted relationship to official curriculum; she promotes the 'Big Five' but asserts the right of educational professionals to make decisions about curriculum delivery. Comments on this post were overwhelmingly supportive of the blogger and critical of the reading program which was variously described as "pre-packaged", "canned", "manufactured" and "from a toolbox".

In describing her reaction to dismissal, Niles Peterson refers to the support she experienced from her Personal Learning Network (PLN): 
The educators in my network consistently amaze me by the quality of resources they share, and by the amount of reflection they do together. The value of this new community is immeasurable and I am truly thankful I found them. (Posted Aug 2010)

Together, Niles Peterson and her commentators are producing a form of professional practice which is intertextual, relational and networked. The sharing of resources is understood to be a crucial practice in maintaining this community.

\section{The Teacher Toolbox}

This educational blog was created by Australian Adrian Bruce and works in tandem with another website (Educational Resources of Adrian Bruce, 2010), which is devoted to distributing educational resources. Bruce, a former primary teacher and current consultant, works seamlessly across several platforms. He produces resources and uploads them to his commercial site, blogs, tweets, and maintains a Facebook presence. His blog posts and Facebook updates point to specific resources while the commercial site hosts the complete resource collection. This collection is being updated regularly.

Bruce's background is in mathematics teaching. His move into digital methods, where he has garnered a reputation as an award winning innovator, has provided a base of influence for broadening his professional territory to include literacy. About a quarter of his blog topics relate directly to literacy including reading comprehension, writing, phonics, games, digital storytelling and readers' theatre.

"Adrian Bruce's Literacy Stuff" is a sub-section of the resources site, a counterpart to the more developed "Maths Stuff" section which was established earlier. Many of the resources offered are in the category of games. The invention and appropriation of games for use in both the mathematics and literacy classroom is a hallmark of Bruce's approach. Cartoon graphics including a comic monster representing the character of Adrian seem intended to reassure teachers that the materials will be engaging and enjoyable for their students.

Conventional printed materials are the norm in the resource collection; only a minority of the resources offered actually require digital technologies in use. A typical example from the literacy page is a conventional card game on the 'bossy e' rule. Teachers are supplied with instructions on how to make this game and play it with students. As with most of the reading resources, phonics underpins the approach.

Teacher Toolbox, on one level, represents the contents of a primary school teacher's filing cabinet, converted into digital files. Bruce presents a rationale for this approach when he writes:

During one of my lectures I talk about how as teachers, so much of our effort goes into paperwork that is later destroyed once the time period dictated by law has passed. I know that we have to do this work and I'm not complaining about it, but as a result of this paperwork teachers don't often leave a legacy for others to benefit from. This is why I put many of my resources online. If I spent the time making the resources and if I found them useful then I'm sure others will as well.

Thus digital conversion is a means of conservation of teachers' work, of passing on the 'legacy' to new generations of educators. 
Like Niles Peterson, Bruce also at times weaves personal reflections into this educational commentary. For instance, he describes moments he has shared with this young daughter during which they have been reading or playing language games together:

Miss Emily usually arises between 5.00 am and 5.30 and it is my job to entertain her so the rest of the house can get some sleep. This morning we had a nice father/daughter moment when we composed a 'fill in the gaps' poem.

It needs to be noted that there was a lot of soft chuckles as we remembered some recent 'terms of endearment'.

Here Bruce the parent and Bruce the teacher merge in the identity of the resourceful individual, ready with an educational activity at hand, suitable for every occasion. The warmth of the writer's tone conveys that choosing and using resources is an aspect of care, not just a technical decision.

Discussion: Digital Bricolage and Other New Literacies for Teacher Professionalism

We have presented these four cases in some detail so as to give readers a sense of the range of agents utilising the digital arena to provide resources for literacy teaching, their expressed intentions in doing so, the strategies they employ, and the responses of practitioners who are accessing and contributing to these sites. Several issues emerge from this analysis.

Teachers have always made their own resources and often learned this skill in pre-service training. In past times, the resources produced by teachers took such forms as printed worksheets, wall posters and concrete materials. Much of what can be found online is a continuation of this activity - the "old wine in new bottles" phenomenon (Lankshear \& Bigum, 1999, p. 455). Adrian Bruce's Teacher Toolbox offers traditional games, posters and worksheets, held in digital form until they are printed off and become hard texts on a classroom wall or student's desk. Even some of the media resources are digitisations of analogue media products; the highly rated Nouns Grammar Rock animation on TeacherTube looks like a decades old television clip. Indeed, digitisation is as likely to be used for conservation as for innovation.

However, the affordances of digital technology are offering teachers new possibilities in literacy resource production. Digital technologies expand the potential for 'bricolage' (Levi-Strauss (1966), the construction of objects for use from the means at hand. Both objects and means can be understood as either concrete or intellectual. The 'means at hand' now includes texts, images, sound files, and so forth which can be downloaded via the internet and a myriad of software programs with which to work on these materials. Teachers' craft orientation to their work has contributed to their characterisation as 'bricoleurs' (Hatton 1988, Reilly 2009). We are now seeing a new category of educational bricoleur; the practitioner who engages in the assemblage, promotion and circulation of digital resources.

This bricolage can be seen in the activities of a TES 'content partner' like cariad 2 who combines and recombines artefacts from her own teaching program with those of other cyber peers to assemble resource packages. Digital assemblage makes possible the combination of the old and the new. It can be understood as an exercise in intertextuality (Lemke, 1995) which challenges division between old and new literacies.

Limited technical proficiency does not appear to deter teachers in their desire to create and share artefacts of their teaching. TeacherTube videos are mainly very 
basic productions and hundreds are uploaded every week. This challenges the common representation of teachers as reluctant to use ICTs owing to lack of experience or knowledge. Perhaps as ICTS become more embedded in everyday life, their take-up in teaching is less of a hurdle than previously. This is supported by a recent study where Reidy and Carson (2010) found that a significant number of surveyed high school teachers were downloading and using software and digital tools for presentation, collaboration, and data analysis in addition to the more traditional worksheets in digital form.

These activities suggest that teacher professionalism in contemporary times involves new literacy practices in addition to conventional modes of using textual resources in teaching. Based on our case study, these include the ability to use production technologies such as video, to produce resources in multiple modalities, to convert existing hard copy texts and analogue media materials to digital form, to upload and download different kinds of files, to compose text for communicating in online forums, to sift through large quantities of online material of varying quality to find what is useful, and to network with peers using multiple platforms.

Many educators clearly wish to circulate the literacy teaching resources that they have made or found, employing the affordances of digital technologies. For some, this means uploading documents to a digital repository like TeacherTube. For others, it means creating their own resource sites and perhaps eventually (as in the cases of Niles Peterson and Adrian Bruce) making this their main professional activity. The scale of peer resource provision online is truly significant.

It is clear that educators are actively seeking for literacy teaching resources online and they value the resources that are produced by peers. One challenge for providers of sharing platforms is quality control. TeacherTube shows what happens when regulation is minimal or absent. Users genuinely interested in finding resources for literacy teaching must trawl through misleading or irrelevant topics, subversive games, spam and advertising. The case of TES shows the value of having dedicated personnel engaged in soliciting and managing the site's resources and user participation.

Another challenge is generating authentic audience and community. A third of surveyed videos in TeacherTube's Writing Channel had received no views and many had just a handful of viewers. Many posts on TES had few respondents. In our larger cohort we found many examples of sites with even more limited interaction. The case of TWRC Tank illustrates some of the features which may contribute to fuller engagement. Julie Niles Peterson wove personal, professional, and conceptual threads into her communications, enabling readers to find more than one point of connection. She provided a rationale for selecting those resources which she offered on her site, presenting them as a curated collection rather than just an ad hoc set. She articulated a standpoint on contemporary debates in literacy teaching which attracted those of like mind.

This study has reinforced the value of viewing teachers as producers, adaptors and active seekers of literacy teaching resources rather than simply as users. The next phase of our study will involve consulting teachers about their resourcing practices broadly and the role of digital provision specifically. Still to be considered include the role of locality and globalisation in teachers' resource access and deployment. It is worth pointing out that both the UK and the US based sharing platforms (TES and TeacherTube) are accessed by significant numbers of teachers from countries outside these nations. But are these 'outsiders' contributing content proportional to their numbers? And how is this 'outside' content viewed by those at the centres? It will be 
important to ask these and other questions related to issues of power and social justice in online resourcing of literacy teaching.

\section{References}

Bryan, H. (2004). Constructs of teacher professionalism within a changing literacy landscape. Literacy, 38(3), 141-148.

Bruce, A. (2010). Teacher Toolbox. Retrieved April 12 ${ }^{\text {th }}$, 2012, from http://adrianbruce.com/teacher-toolbox.

Carlson, B., \& Reidy, S. (2004). Effective access: Teachers' use of digital resources (Research in Progress). OCLC Systems and Services, 20(2), 65-70. doi:10.1108/1065075041053068.

Comor, E. (2011). Contextualizing and critiquing the fantastic prosumer: Power, alienation and hegemony, Critical Sociology, 37(3), 309-327. doi: $10.1177 / 0896920510378767$

English Spelling Problems (2007). http://www.englishspellingproblems.co.uk. Accessed $12^{\text {th }}$ April 2012.

Fang, Z., Fu1, D., \& Lamme, L. (2004). From scripted instruction to teacher empowerment: Supporting literacy teachers to make pedagogical transitions. Literacy, 38(1), 58-64. doi: 10.1111/j.0034-0472.2004.03801010.x

Handsfield, L., Crumpler, T., \& Dean, T. (2010). Tactical negotiations and creative adaptations: The discursive production of literacy curriculum and teacher identities across space-time. Reading Research Quarterly, 45(4), 405-431.

Hatton, E. J. (1988). Teachers' work as bricolage: Implications for teacher education. British Journal of Sociology of Education, 9(3), 337-357.

Hur, J.W., \& Brush, T.A. (2009). Teacher participation in online communities: Why do teachers want to participate in self-generated online communities of K-12 teachers? Journal of Research on Technology in Education, 41(3), 279-303.

Lankshear, C., \& Bigum, C. (1999). Literacies and new technologies in school settings. Pedagogy, Culture \& Society, 7(3), 445-465.

Lemke, J. (1995). Textual politics: Discourse and social dynamics. London, UK: Taylor \& Francis.

Levi-Strauss, C. (1966). The savage mind. Chicago, IL: University of Chicago Press.

Nichols, S., Rowsell, J., Nixon, H., \& Rainbird, S. (2012). Resourcing early learners: New networks, new players. New York, NY: Routledge.

Niles Peterson, J. (2011). TWRC Tank. Retrieved February $16^{\text {th }}$, 2012, from http://twrctank.com.

Owens, D. (2010). Commercial reading programmes as the solution to children living in poverty. Literacy, 44(3), 112-121. doi: 10.1111/j.1741-4369.2010.00548.x

Reilly, M. (2009). Opening spaces of possibility: The teacher as bricoleur. Journal of Adolescent \& Adult Literacy, 52(5), 376-384. doi: 10.1598/JAAL.52.5.2

TeacherTube (2010). http://teachertube.com/staticPage.php?pg=about. Accessed February $9^{\text {th }}, 2012$.

TES (2011). http://www.tes.co.uk/. Accessed April 12 $2^{\text {th }}, 2012$.

\section{Author Biographies}

Susan Nichols is senior lecturer in literacy education at the University of South Australia. Her research crosses sites of practice from classrooms to homes, 
communities and institutions, on and offline. Her work has been published in numerous edited books and journals including Literacy, International Journal of Qualitative Studies in Education, English in Australia and the Journal of Early Childhood Literacy.

Amy Maynard, while a graduate student in Communication at the University of South Australia, won a student research scholarship to work on the project Teachers on the Web. Her personal research focus has been on the practices of comic book reading and production and she is currently a freelance writer.

Christopher Brown, a graduate student in Education at the University of South Australia, won a student research scholarship to work on Teachers on the Web before taking up a position as research assistant on the project. His current research concerns socially just pedagogies for students living in disadvantaged communities. 